\title{
Mycosis Fungoides in Black Patients: Time for a Better Look
}

\author{
Patricia Myskowski, MD
}

1 ecent advances in the immunopathogenesis and therapy of cutaneous T-cell lymphoma (CTCL) have shown great promise for the care of patients with mycosis fungoides (MF) and Sézary syndrome (SS). ${ }^{1-3}$ Research into the tumor microenvironment, microbiome, and molecular genetics may yield further information as we strive to develop MF/SS therapy from the bench to the bedside. $^{3}$ Although progress has been made on multiple fronts in $\mathrm{MF}$, some important-particularly epidemiologic and clinical-questions remain unanswered.

Racial disparities are well known to exist in CTCLs, particularly MF and SS. ${ }^{4-7}$ The incidence of MF and SS in the United States is higher in African American/Black patients than in White patients ${ }^{4}$; in addition, MF has an earlier age at onset in Black patients compared with White

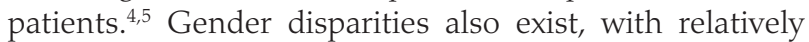
more Black females than males affected with $\mathrm{MF}^{4-6}$; in particular, early-onset MF (ie, $<40$ years of age) is more common in Black females than Black males. 6,7 According to Surveillance, Epidemiology, and End Results (SEER) data $^{4}$ and the US National Cancer Database, ${ }^{5}$ African American/Black patients with MF have worse outcomes compared with other races (shorter overall survival and higher mortality) and also exhibit higher stages of disease at presentation (stage IIb or higher). ${ }^{5}$ Black race also was found to be a predictor of poor overall survival after accounting for disease characteristics, socioeconomic factors, and types of treatment. The factors responsible for these racial disparities remain unclear.

A fortuitous collision of interests and technology may have helped to shed light on some of the reasons for these racial disparities in MF. Nearly 2 decades ago, high-quality, whole-body digital cutaneous photography was implemented by the Dermatology Service at Memorial Sloan Kettering Cancer Center Dermatology
Service (New York, New York) ${ }^{8}$ Although the standardized 20-pose positioning images initially were used for the follow-up evaluation of patients with multiple nevi and melanomas, we incorporated the same photography technique into our multidisciplinary Cutaneous Lymphoma Clinic at Memorial Sloan Kettering Cancer Center. The multiplicity and clinical heterogeneity of MF lesions is well known, as is the fact that individual MF lesions may develop, respond to therapy, or change independently of other lesions in a given patient. We regularly reviewed these digital images with patients during their visits to assess treatment responses, discussed the need for changes in therapy in the face of progressive disease, and provided encouragement and positive reinforcement for those who improved with time-consuming regimens (eg, phototherapy).

Ultimately, as we became more familiar with looking at images in skin of color, we recognized different clinical features among our Black patients. In the literature, hypopigmented MF is a variant that typically is characterized by $\mathrm{CD}^{+}$-predominant $\mathrm{T}$ cells and is seen more frequently in dark-skinned patients. ${ }^{9}$ In contrast, hyperpigmented MF has been considered a relatively rare presentation of $\mathrm{MF} .^{10}$ However, using only clinical and demographic information, we were able to identify 2 very different prognostic groups: those with hypopigmented lesions and those with only hyperpigmented and/or erythematous skin lesions. ${ }^{11}$ In our retrospective review of 157 African American/Black MF patients at our institution-122 with early-stage and 35 with late-stage $\mathrm{MF}-45 \%$ of patients had hypopigmented lesions vs $52 \%$ with hyperpigmented and/or erythematous lesions but no hypopigmentation. Those with hypopigmentation had superior outcomes, with better overall survival $(P=.002)$ and progression-free survival $(P=.014)$.

From the Dermatology Service, Division of Subspecialty Medicine, Department of Medicine, Memorial Sloan Kettering Cancer Center, New York, New York, and the Department of Dermatology, Weill Cornell Medical College, New York.

The author reports no conflict of interest.

Funded by P30 CA008748 MSK Cancer Support Grant/Core Grant.

Correspondence: Patricia Myskowski, MD (myskowsp@mskcc.org).

doi: $10.12788 /$ cutis.0247 
In addition, more than $80 \%$ of patients who progressed or died from disease had hyperpigmented and/or erythematous lesions without hypopigmentation. ${ }^{11}$

Sometimes we have to go backward to go forward. Going from the bedside to the bench in our Black MF/SS patients-initially through the clinical recognition of prognostically different lesions, and then through clinicopathologic correlation with immunophenotyping and molecular studies_-should provide important clues. Further investigation of Black patients who share similar pigmentary phenotypes of MF also may shed light on the pathogenetic mechanisms responsible for these prognostically significant skin findings. Through these efforts, we hope to identify higher-risk patients, which ultimately will lead to earlier intervention, more effective therapeutic regimens, and improved outcomes.

\section{REFERENCES}

1. Durgin JS, Weiner DM, Wysocka M, et al. The immunopathogenesis and immunotherapy of cutaneous T cell lymphoma: pathways and targets for immune restoration and tumor eradication. J Am Acad Dermatol. 2021;84:587-595

2. Weiner DM, Durgin JS, Wysocka M, et al. The immunopathogenesis and immunotherapy of cutaneous $\mathrm{T}$ cell lymphoma: current and future approaches. J Am Acad Dermatol. 2021;84:597-604.
3. Quaglino P, Fava P, Pileri A, et al. Phenotypical markers, molecular mutations, and immune microenvironment as targets for new treatments in patients with mycosis fungoides and/or Sézary syndrome. J Invest Dermatol. 2021;141:484-495.

4. Nath SK, Yu JB, Wilson LD. Poorer prognosis of African-American patients with mycosis fungoides: an analysis of the SEER dataset, 1988 to 2008. Clin Lymphoma Myeloma Leuk. 2014;14:419-423.

5. Su C, Nguyen KA, Bai HX, et al. Racial disparity in mycosis fungoides: an analysis of 4495 cases from the US National Cancer Database. J Am Acad Dermatol. 2017;77:497-502.

6. Balagula Y, Dusza SW, Zampella J, et al. Early-onset mycosis fungoides among African American women: a single-institution study. J Am Acad Dermatol. 2014;71:597-598.

7. Virmani P, Levin L, Myskowski PL, et al. Clinical outcome and prognosis of young patients with mycosis fungoides. Pediatr Dermatol. 2017;34:547-553

8. Halpern AC, Marghoob AA, Bialoglow TW, et al. Standardized positioning of patients (poses) for whole body cutaneous photography. J Am Acad Dermatol. 2003;49:593-598.

9. Rodney IJ, Kindred C, Angra K, et al. Hypopigmented mycosis fungoides: a retrospective clinicohistopathologic study. J Eur Acad Dermatol Venereol. 2017;31:808-814

10. Kondo M, Igawa K, Munetsugu T, et al. Increasing numbers of mast cells in skin lesions of hyperpigmented mycosis fungoides with largecell transformation. Ann Dermatol. 2016;28:115-116.

11. Geller S, Lebowitz E, Pulitzer MP, et al. Outcomes and prognostic factors in African American and Black patients with mycosis fungoides/ Sézary syndrome: retrospective analysis of 157 patients from a referral cancer center. J Am Acad Dermatol. 2020;83:430-439.

\section{NEW \\ RESIDENT CORNER Contributors}

\section{Our Resident Corner online features commentaries from:}

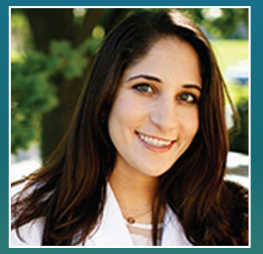

Soraya Azzawi, MD

University of Miami/Jackson

Memorial Hospital

Miami, Florida

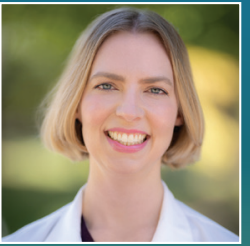

Margaret Maria Cocks, MD, PhD University of Utah School of Medicine Salt Lake City, Utah

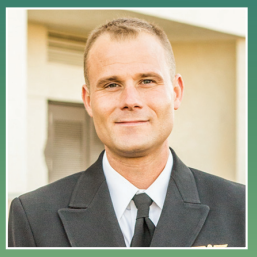

W. Hugh Lyford, MD

Naval Medical Center San Diego San Diego, California

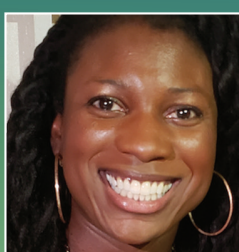

Nicole A. Negbenebor, MD

Warren Alpert Medical School of Brown University

Providence, Rhode Island 